\title{
Penerapan Management Bandwidth Menggunakan Hierarchical Token Bucket Pada PT. Indomarco Prismatama
}

\author{
Siti Maesaroh ${ }^{* 1}$ \\ Gilang Kartika Hanum ${ }^{2}$ \\ Suryazi Rajab ${ }^{3}$ \\ $1 \& 2$ Program Studi Sistem Informasi, Fakultas Sains dan Teknologi, Universitas Raharja \\ ${ }^{3}$ Program Studi Teknik Informatika, Fakultas Sains dan Teknologi, Universitas Raharja \\ E-mail: ${ }^{1 *}$ Siti.maesaroh@raharja.info,${ }^{2)}$ Gilanghanum@raharja.info , \\ ${ }^{3}$ Suryazi.rajab@raharja.info
}

\begin{abstract}
Abstrak
Penggunaan akses internet saat ini sangatlah berketergantungan, baik untuk keperluan pribadi maupun dalam bekerja.Pemakaian akses internet oleh pengguna atau client yang seringkali digunakan secaraan bersamaan, dengan adanya perihal tersebut dapat mempengaruhi kecepatan yang didapatkan oleh pengguna atau client. Oleh karena itu perlu dilakukannya penyesuaian bandwidth, agar tidak terjadinya ketidakadilan dalam mengakses suatu jaringan internet. Untuk penyesuian bandwidth tersebut, maka diperlukannya management bandwidth. Dengan adanya management bandwidth, paket data internet dapat mengelola bandwidth pada setiap pengguna atau client. Metode yang akan digunakan pada managementbandwidth adalah dengan menggunakan metode Hierarchical token bucket. Dengan metode tersebut, dapat melimitasi kebutuhan akses internet sesuai dengan kebutuhan perusahaan. Hal tersebut sangatlah penting dalam suatu perusahaan, dikarenakan dalam penggunaan akses internet tidak hanya menggunakan komputer saja tapi ada pengguan internet dengan menggunakan laptop atau smartphone yang status IP nya bersifat dinamis.
\end{abstract}

Kata Kunci :Management, bandwidth, Hierarchical Token bucket

\begin{abstract}
Usage The use of internet access today is highly dependent, both for personal use and at work. The use of internet access by users or clients which are often used simultaneously, with this matter can affect the speed obtained by users or clients. Therefore, it is necessary to adjust the bandwidth, so that there is no injustice in accessing an internet network. For the bandwidth adjustment, bandwidth management is needed. With bandwidth management, internet data packages can manage bandwidth for each user or client. The method that will be used in bandwidth management is using the Hierarchical token bucket method. With this method, you can limit the need for internet access according to the company's needs. This is very important in a company, because the use of internet access does not only use computers but there are internet users using laptops or smartphones whose IP status is dynamic.
\end{abstract}

Keyword :Management, Bandwidth, Hierarchical Token bucket

\section{PENDAHULUAN}


Penggunaan internet yang dilakukan secara bersamaan, dengan pengguna yang cukup banyak dapat mengakibatkan turunnya kualitas jaringan. Untuk mengurangi penurunan kualitas jaringan tanpa menambah bandwidth dan biaya, salah satunya dengan cara menerapkan management dengan menggunakan disiplin antrian atau teknik QoS (Quality Of Services) tertentu, Quality of Service $(Q o S)$ merupakan metode pengukuran tentang seberapa baik jaringan dan merupakan suatu usaha untuk mendefinisikan karakteristik dan sifat dari satu service.Quality of Service digunakan untuk mengukur sekumpulan atribut kinerja yang telah dispesifikasikan dan diasosiasikan dengan suatu servis. Parameter - parameter Quality ofService terdiri dari Throughput, Packet Loss, Delay (Latency) dan Jitter[1]. interkoneksi antar dua komputer atau lebih yang saling terhubung dengan sebuah media transmisi yaitu menggunakan kabel atau tanpa kabel wireless[2], management bandwidth sangat berperan dalam mengatur jenis aplikasi yang bisa mengakses joins yang ada. QoS dengan metode - metode Various leveled Token Can (HTB) sebagai salah satu management data transfer kapasitas ideal diterapkan di dalam sistem operasi Mikrotik.

bandwidth merupakan kapasitas atau daya tampung kabel ethernet agar dapat dilewati trafik paket data dalam jumlah tertentu.Bandwidth juga biasa berarti jumlah konsumsi paket data per satuan waktu dinyatakan dengan satuan bit per second (bps) management bandwith juga digunakan untuk memastikan bandwidth yang memadai untuk memenuhi kebutuhan trafik data dan informasi serta mencegah persaingan antara aplikasi[3]. Management Bandwidth adalah pengalokasian yang tepat dari suatu bandwidth untuk mendukung kebutuahan atau keperluan aplikasi atau suatu layanan jaringan. Pengalokasian bandwidth yang tepat dapat menjadi salah satu metode dalam memberikan jaminan kualitas suatu layanan jaringan Quality of Service $(Q o S)[4]$.

Penggunaan jaringan internet pada PT. Indomarco Prismatama ini masih ada beberapa pengguna yang sering mendapatkan akses yang tidakstabil.Management bandwidth yang bisa secara otomatis membagi traffic per-client berdasarkan jumlah user yang aktif.Namun memiliki kelemahan kadangkala terjadinya kebocoran pada bandwidth tidak secara merata terbagi dengan adil. Oleh karena itu perlu diterapkan management baru tanpa harus mengurangi kelebihan yang sudah ada, yaitu management bandwidth tipe (Hierarchical Token Bucket), yang menjamin pengguna jaringan mendapatkan bandwidth sesuai dengan yang telah didefinisikan dan juga terdapat fungsi pembagian bandwidth yang adil di antara pengguna jaringan sehingga performa jaringan tetap dapat terjaga. Metode Hierarchical Token Bucket (HTB) merupakan salah satu metode yang digunakan untuk mengoptimalkan jaringan dari segi management bandwidth. Metode HTB ini memberikan kemudahan pemakaian dengan teknik peminjaman dan implementasi pembagian trafik yang lebih akurat serta dapat memudahkan pengelola jaringan yang berbasis wireless, sehingga tidak terjadi rebutan bandwidth antar client karena sudah dilakukan manajemen dari setiap client[5].

\section{METODE PENELITIAN}

Beberapa metode penelitian yang digunakan agar memperoleh data yang lengkap dan benar adalah:

\subsection{Metoda Perancangan}

Dalam merancang sistem yang diusulkan pada penelitian ini, penulis merancang diagramdiagramnya menggunakan UML (Unified Modelling Language) diantaranya usecase,activity, sequence dan class diagram, dan untuk bahasa program yang digunakan yaitu PHP dengan database MySQL.

\subsection{Metoda Pengembangan}

Dalam laporan skripsi ini, metode pengembangan dengan menggunakan HTB 
(Hierarchical Token Bucket) teridiri dari langkah - langkah sebagai berikut;

1) Membuat queue tree di Mikrotik yang terdiri dari class dan parent, yang harus diisi dengan outgoing-interface.

2) Menentukan max-limit di setiap class dan parent yang merupakan batas kecepatan maksimal, atau sering dikenal dengan MIR (Maximum Information Rate).

\section{2.3Tinjauan Pustaka}

1. Penelitian ini dilakukan oleh Alvin Riady dan Aan Restu Mukhti (April, 2021) yang berjudul "Penerapan Manajemen Bandwith Menggunakan Hierarchical Token Bucket Di PT. Bukit Energi Servis Terpadu". Penelitian ini bertujuan untuk untuk mengatasi permasalahan dominasi bandwidth antar pengguna dan bermacam - macam jenis trafik data ketika berjalan bersamaan.

2. Penelitian ini dilakukan oleh Tri Oktafi Sidqi, Iskandar Fitri,Novi Dian Nathashia (2021) yang berjudul "ImplementasiManajemen Bandwidth Menggunakan Metode HTB (Hierarchical Token Bucket) Pada Jaringan Mikrotik”. Adapun penelitian ini bertujuan untuk membagi bandwith secara stabil dan merata. Dengan metode HTB manajemen bandwidth dapat dikelola dengan baik dan lebih efisien karna dengan metode inilah queue yang dibuat dapat lebih terstruktur dan lebih rapih maka routerakan memiliki kineja yang lebih optimal. Dengan cara membagi kelas dalam kelompok parent dan child menjadikan sebuah cara yang baik dalam pembagian traffic internet sehingga user atau client dapat meakukan perputaran data atau informasi sama rata atau akan lebih terstruktur.

3. Penelitian ini dilakukan oleh Arif setiadi, Prita Haryani, Suwanto Raharjo (2021) yang berjudul "Manajemen Pada Jaringan Mikrotik Menggunakan Metode Hierarchical Token Bucket(HTB)Dan Keamanan FirewallIntrusion Detection System (IDS)". Adapun penelitian ini bertujuan untuk menerapkan sistem pemanajemenan bandwidth dan penerapan sistem keamanan agar setiap user dapat menggunakan jaringan internet secara maksimal. Metode yang digunakan untuk pemanajemenan bandwidth menggunakan metode Hierarchical Token Bucket (HTB) dan pada sistem keamanan menggunakan sistem keamanan pingflood dan port knocking. Pada penelitian ini menggunakan metode dengan pendekatan kuantitatif. Metode kuantitatif digunakan untuk pengukuran parameter jaringan berupa nilai throughput, packet loss, delaydan jitter.

4. Dalam jurnal yang berjudul "Desain Infrastruktur Jaringan Komputer dengan Metode Hierarchical Token Bucket menggunakan Mikrotik pada Badan Kesatuan Bangsa dan Politik" di buat oleh M.Daffa, Aliffandhana and Imam, Asrowardi and Dewi, Kania Widyawati (2019)Menjalaskan tentang pembangunan jaringan bertujuan untuk membantu dalam penyampaian informasi serta menata ulang jaringan komputer pada instansi menjadi tepat. Berdasarkan data penelitian sebelum menggunakan metode hierarchical token bucket parameter jaringan seperti troughput rata-rata memperoleh nilai $196 \mathrm{~Kb}$, setelah menerapkan metode hierarchical token bucket pada infrastruktur jaringan komputer menghasilkan nilai troughput rata-rata $246 \mathrm{~Kb}$ dan menjadi infrastruktur jaringan komputer instansi mengalami peningkatan.

5. Penelitian ini dilakukan oleh Tobby Octavianto (2021) dengan judul "Pemanfaatan Hierachical Token Bucket Dalam Konsep Jaringan Untuk Pengoptimalan Bandwidth". Adapun tujuan dari penelitian ini yaitu dapat diatur besar bandwidth maksimal untuk masing-masing client dengan demikian penggunaan saat download oleh client untuk mendapati bandwidth lebih dapat teratasi.

6. Penelitian ini dilakukan oleh Ketut Gede Widia Pratama Putra, (2020) yang berjudul "Penerapan Manajemen Bandwidth Menggunakan Metode Hierarchical Token Bucket 
Pada Layanan Hotspot Mikrotik UNDIKSHA". Penelitian ini bertujuan untuk mengetahui Penerapan manajemen bandwidth menggunakan Hierarchical Token Bucket (HTB) pada layanan hotspotmikrotik Undiksha..

7. Penelitian ini dilakukan oleh Ardian Fadli, (2018) yang berjudul "Implementasi Quality Of Service pada Campus Network Menggunakan Teknologi Software-Defined Networking dan Opendaylight Controller dengan Metode Hierarchical Token Bucket". Penelitian ini bertujuan untuk meningkatkan kualitas layanan pada jaringan dengan memberikan jaminan bandwidth untuk setiap service yang berjalan. Peningkatan jumlah pengguna internet pada jaringan kampus secara otomatis akan mempengaruhi kualitas layanan pada jaringan tersebut. Maka dari itu diperlukan sebuah sistem yang dapat meningkatkan kualitas layanan jaringan dengan melakukan limitasi bandwidth untuk setiap service yang berjalan. Hierarchical Token Bucket (HTB) merupakan salah satu metode dalam pengalokasian bandwidth. HTB bertugas melakukan limitasi bandwidthdan mengatur antrian paket berdasarkan prioritas. Penerapan metode HTB dilakukan menggunakan teknologi Software-Defined Networking (SDN). SDN merupakan teknologi jaringan yang menggunakan OpenFlow sebagai protokolnya. OpenDaylight merupakan salah satu controller berbasis SDN yang mendukung protokol OpenFlow. Metode HTB dihubungkan pada OpenDaylightcontroller menggunakan fitur restAPI. Hasil dari pengujian menunjukan bahwa metode HTB dapat berjalan dengan baik dalam melakuka limtasi bandwidth dan mampu meningkatkan kualitas layanan jaringan dengan memberikan jaminan bandwidth pada setiap service yang telah ditentukan.

8. Penelitian ini dilakukan oleh Sugianto dan Mimin F Rohmah, (2018) yang berjudul "Perbandingan Performance Managemen Bandwidth Metode Hierarchical Token Bukcet (HTB) Dan Per Connection Queue Menggunakan Mikrotik RB-450G'. Penelitian ini bertujuan untuk mencegah terjadinya monopoli penggunanaan bandwidth yaitu dengan melakukan $Q o S$ (Quality of Service) atau dikenal sebagai manajemen bandwidth, sehingga semua client bisa mendapatkan jatah bandwidth masing-masing. Mikrotik memiliki QoS (Quality of services) yang di gunakan untuk mengatur penggunaan bandwidth secara rasional. Penelitian ini melakukan percobaan perbandingan performancemanagementbandwidth dengan dua metode yang berbeda. Metode yang digunakan adalah Hierarchical Token Bucket (HTB) dan Per Connection Queue (PCQ) dengan menggunakan mikrotik RB450G. Hasil dari penelitian ini setelah dilakukan pengujian dengan memaksimal bandwidth sebesar 2 MB untuk sekenario proses upload sebanyak 5 data dan download sebanyak 10 data, bahwa nilai parameter throughput, rata delay dan packet loss pada aktifitas download metode Hierarchical Token Bucket (HTB) lebih baik dalam menangani masalah manajemen bandwidth dengan nilai rata-rata throughput $\pm 1.56 \mathrm{Mbps}$, rata delay \pm 0.00428146 second dan persentase packet loss $\pm 0.03553 \%$. Untuk aktivitas upload rata-rata nilai rata delay Metode Per Connection Queue (PCQ) lebih baik dibandingkan dengan metode Hierarchical Token Bucket (HTB) dengan nilai 0.032139298 second.

9. Penelitian ini dilakukan oleh Esdinar Manalu, Diki Arisandi, Sukri (2017) yang berjudul "Analisa Management Bandwidth Dengan Metode Antrian Hirarchical Token Bucket". Penelitian ini bertujuan untuk menerapkan kontrol penggunaan internet, menerapkan manajemen bandwidth dan menstabilkan koneksi internet. Metode antrian yang digunakan dalam penelitian ini yaitu menggunakan metode Hierarchical Token Bucket (HTB). Tujuan utama dari metode ini yaitu membuat manajemen bandwidth menggunakan router mikrotik pada jaringan wi-fi dengan metode simple queue untuk mengatasi masalah jaringan internet sehingga dapat membagi bandwidth secara merata kepada setiap user. Dari pengujian yang telah dilakukan perbandingan hasil yang didapatkan adalah jaringan internet yang 
menggunakan metode HTB lebih stabil dibandingkan jaringan internet tanpa metode HTB. Karena ketika menerapkan metode HTB setiap user tidak akan mendapat jatah bandwidth dibawah nilai commited information rate (CIR) sesibuk atau sepadat apapun traffic internet.

10. Penelitian ini dilakukan oleh Ebenhaezer Patandung, dkk (2016) yang berjudul "Analisis Qualityof Service (QoS) Video Streaming Dengan Menggunakan Metode DifferentiatedService dan Hierarchical Token Bucket". Penelitian ini bertujuan untuk mengetahui bagaimana kinerja dari metode DiffServ dan HTB untuk mengetahui nilai Quality of Service $(Q o S)$ dari kedua metode tersebut, sehingga didapatkan metode yang paling cocok untuk $(Q o S)$ video streaming.

\section{HASIL DAN PEMBAHASAN}

\subsection{Rancangan Sistem Usulan}

Beberapa masalah sebelumnya sudah diuraikan memperbaiki masalah yaitu pada sistem akses koneksi internet. Karena faktor-faktor yang sudah disebutkan pada bab sebelumnya. Sistem yang diusulkan untuk memperbaiki pembagian bandwidth dengan metode HTB (Hierarchical Token Bucket). Yang bertujuan agar bandwidth bisa diproses secara bersamaan dan mendapatkan limit yang merata. Dengan seperti itu client tidak akan mendapatkan bandwidth yang tidak merata lagi. 


\section{Use case diagram Admin}

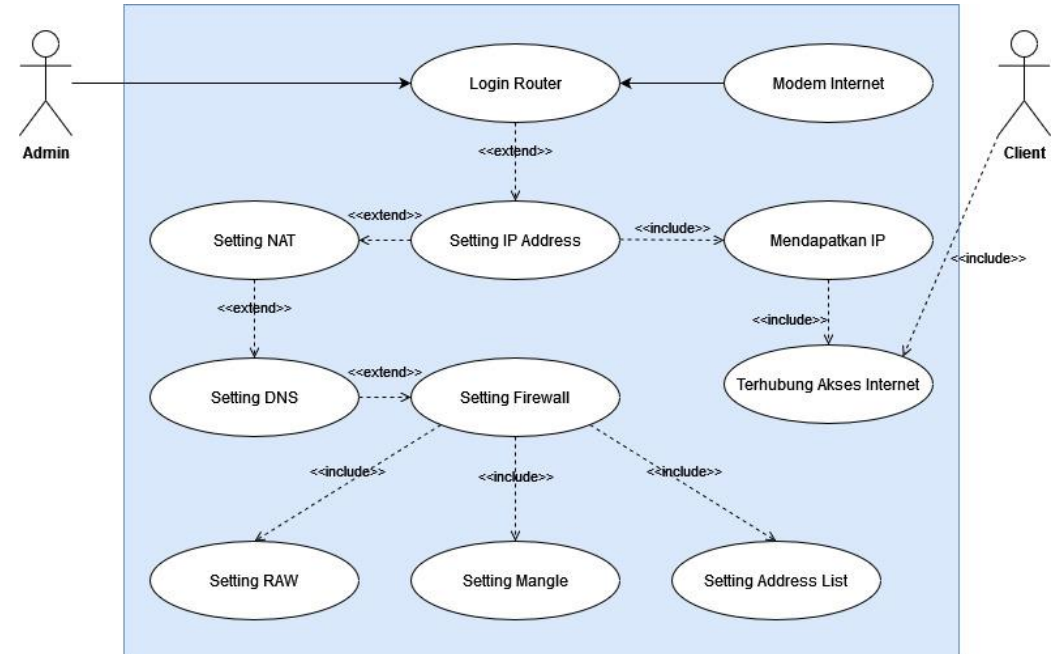

Gambar 1 Use case diagram Admin yang diusulkan

Berdasarkan gambar 1 Use Case Diagram yang diusulkan terdapat 1 buah sistem yang merupakan rancangan usulan system jaringan koneksi internet, 2 aktor yaitu admin dan client dan 11use case dari setiap aktifitas yang akan saling berhubungan pada system jaringan internet ini.

\section{Activity Diagram yang Diusulkan}

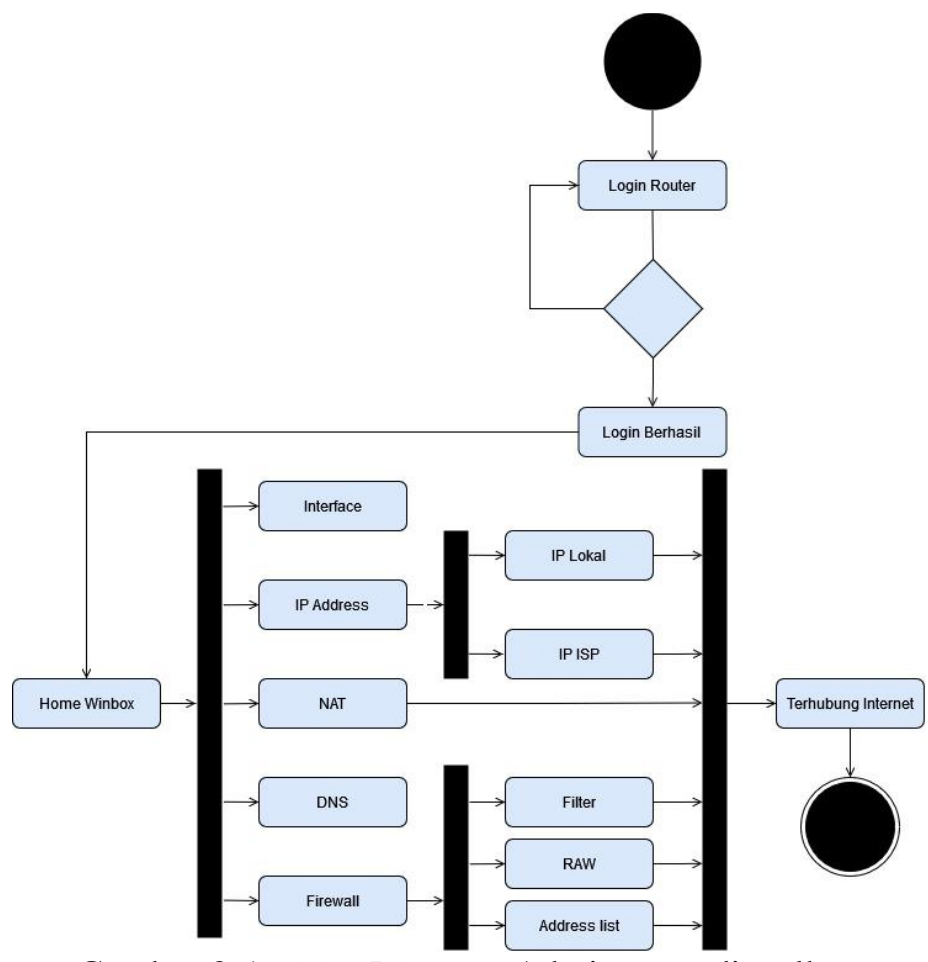

Gambar 2 Activity Diagram Admin yang diusulkan

Berdasarkan Gambar 2 diatas, rancangan activity diagram terdiri dari 1 (satu) initial node dimana objek memulai kegiatan, 4 (empat) fork node yang merupakan pemecah satu aliran yang 
pada tahap tertentu berubah menjadi beberapa aliran pada activity diagram, 14 (empatbelas) action state yang mencerminkan dari suatu aksi, 1 (satu) decision node digunakan untuk pilihan kondisi dan 1 (satu) final node merupakan akhir dari kegiatan admin.

\section{Sequence Diagram Yang Diusulkan}

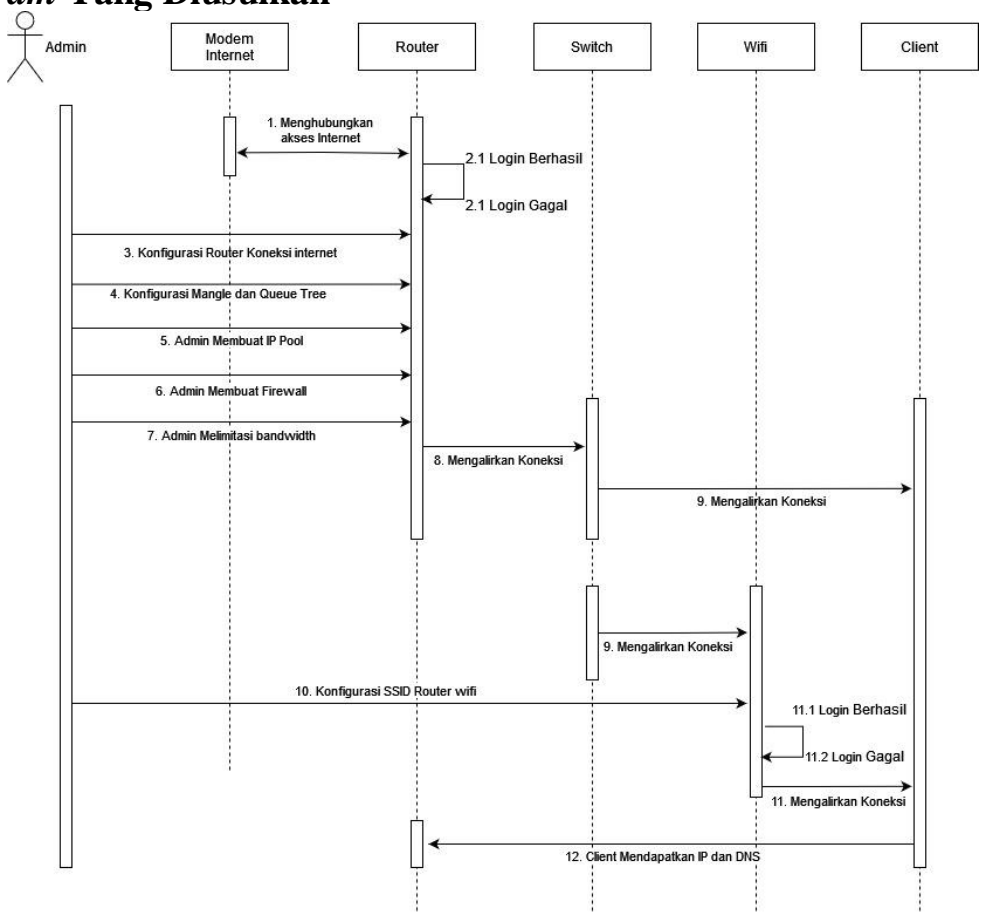

Gambar 3 Sequence Diagram Admin yang diusulkan

Berdasarkan Gambar 3 diatas, rancangan sequence diagram terdiri dari 1 (satu) actor yaitu admin, 5 (lima) life line antarmuka yang saling berinteraksi dan 14 (empat belas) messageyang membuat informasi-informasi tentang aktivitas yang terjadi.

\section{RancanganSkemaJaringanUsulan}




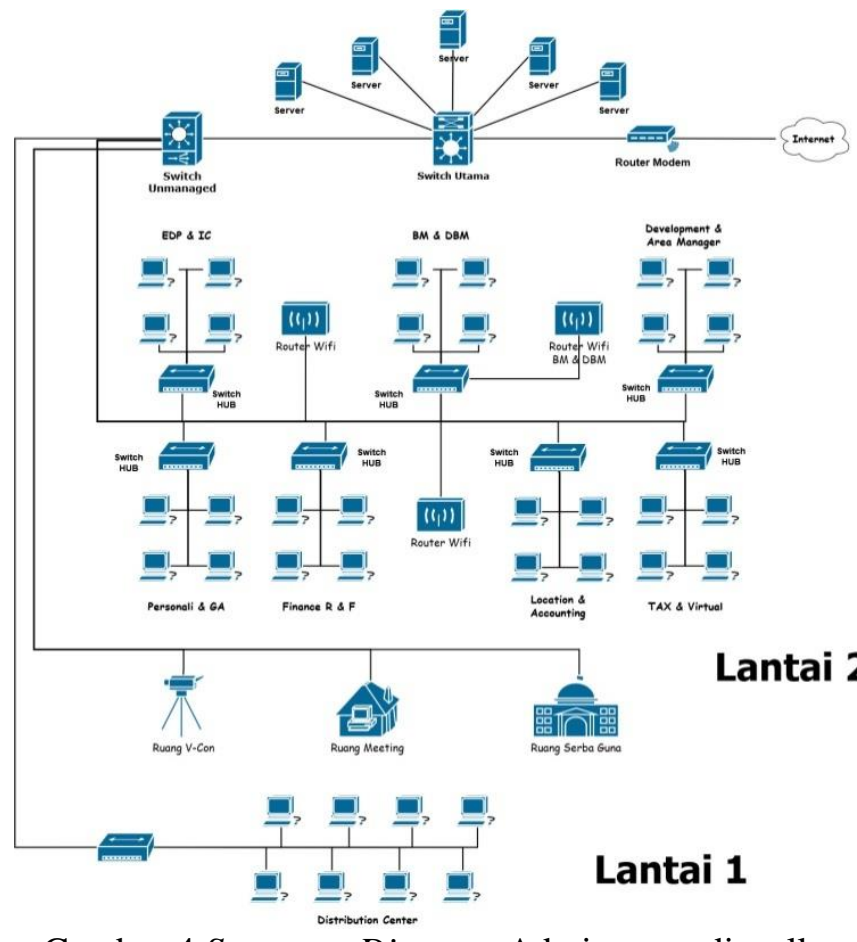

Gambar 4 Sequence Diagram Admin yang diusulkan

Pada skema jaringan usulan diatas dapat dilihat bahwa susunan dan tata letak sudah cukup bagus. Namun banyaknya client, sering terjadinya overload pada penggunaan paket data.

\subsection{Tampilan Program yang Diusulkan}

\section{Tampilan Halaman Login Router}

Halaman ini berisi tampilan untuk login router admin.Login dilakukan dengan menggunakan Username dan Password, seperti gambar di bawah ini.

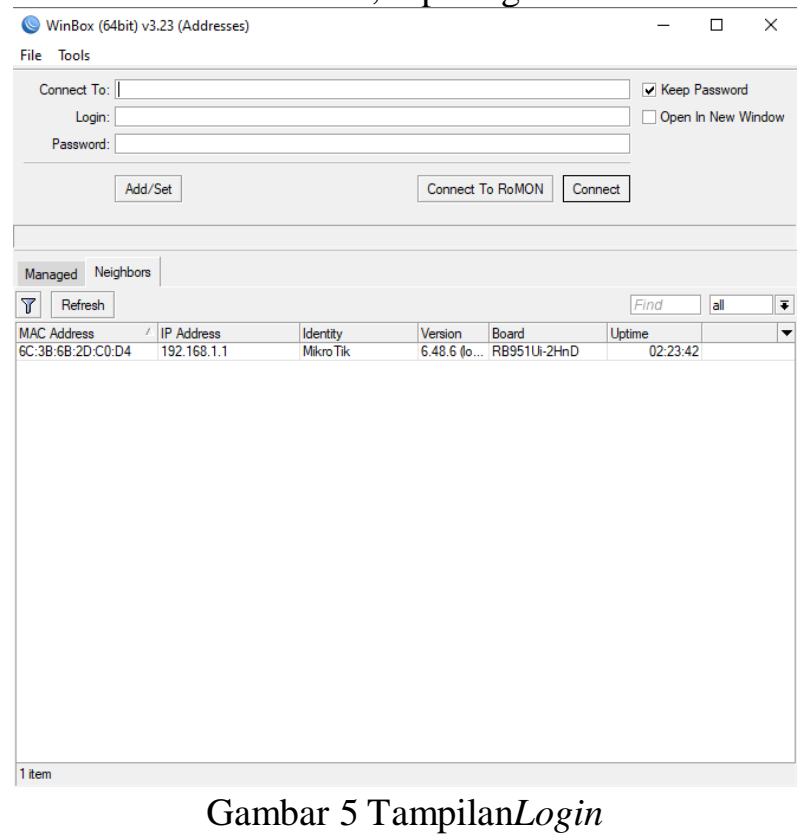




\section{Tampilan Halaman UtamaRouter}

Setelah berhasil login dengan memasukan Username dan Password admin bisa masuk kehalaman utama admin atau dashboard/home dimana admin dapat melihat dan kelola master siswa, master kelas, set kelas, set tahun ajaran konfirmasi pembayaran sampai cetak laporan pelunasan dan tunggakan. Seperti gambar 6 dibawah ini.

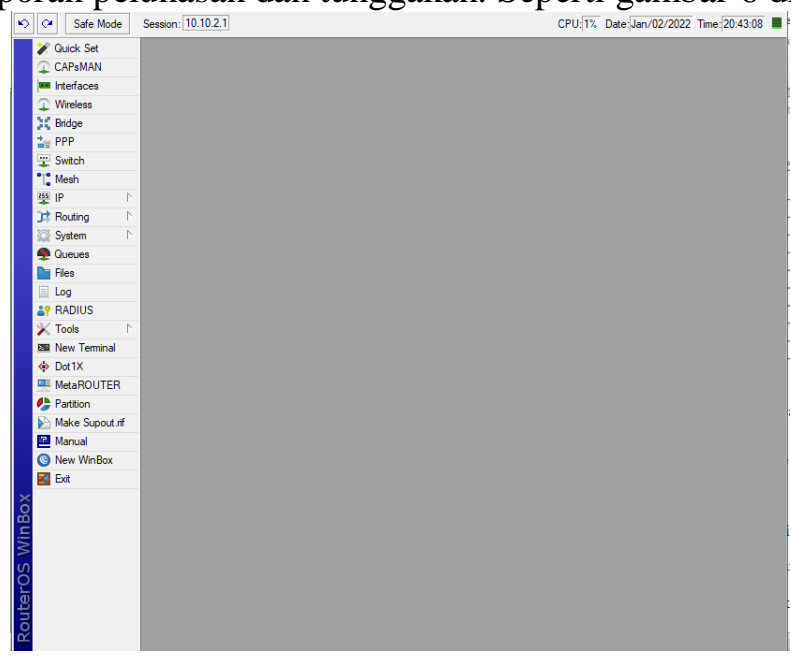

Gambar 6 Tampilan Halaman Utama

3. Tampilan Interface

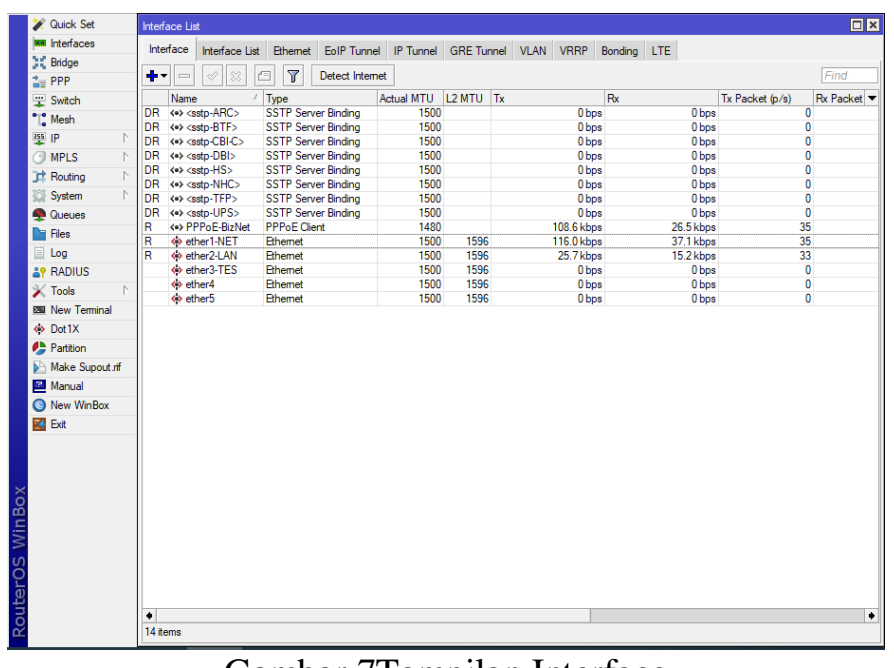

Gambar 7Tampilan Interface

\section{Tampilan ÌP Address}




\begin{tabular}{|c|c|c|c|c|c|c|}
\hline \multirow{2}{*}{$\begin{array}{l}\text { Quick Set } \\
\text { m Interfaces }\end{array}$} & \multicolumn{5}{|c|}{ Address List } & ㅁ口 \\
\hline & & $\square \otimes$ & 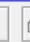 & 8 & & Find \\
\hline Af: Bridge & & Address & 1 & Network & Interface & $\nabla$ \\
\hline${ }_{\square} \mathrm{PPP}$ & D & $\approx 10.43 .1 .1$ & & 10.43.1.13 & $\langle$ sstp-CB|-C $\rangle$ & \\
\hline 菏 Switch & D & $\div$ 10.43.1.1 & & 10.43.1.6 & $\langle$ sstp-NHC $\rangle$ & \\
\hline$\because$ Mesh & D & 10.43.1.1 & & 10.43.1.12 & 〈sstp-UPS〉 & \\
\hline 些 IP IP & $\begin{array}{l}D \\
D\end{array}$ & 하 10.43 .1 .1 & & $\begin{array}{l}10.43 .1 .5 \\
10.431 .7\end{array}$ & $\langle$ 〈sstp-TFP> & \\
\hline MPLS & D & $\div$ 10.43.1.1 & & 10.43.1.3 & $\begin{array}{l}\langle\text { sstp-ARC }\rangle \\
\langle\text { sstp-DBI> }\end{array}$ & \\
\hline It? Routing & D & - 10.43.1.1 & & 10.43.1.2 & 〈sstp-HS> & \\
\hline & D & $\div$ 10.43.1.1 & & 10.43.1.4 & $\langle$ 〈sstp-BTF〉 & \\
\hline System & D & $\div 182.253 .1$ & & 182.253.172.1 & PPPoE-BizNet & \\
\hline Queues & & के 192.168.1 & & 192.168.112.0 & ether2-LAN & \\
\hline Files & & & & & & \\
\hline 刑 $\log$ & & & & & & \\
\hline$\therefore$ RADIUS & & & & & & \\
\hline X Tools & & & & & & \\
\hline New Teminal & & & & & & \\
\hline$\Leftrightarrow \operatorname{Dot} 1 X$ & & & & & & \\
\hline E) Partition & & & & & & \\
\hline Make Supout.rif & & & & & & \\
\hline 巴르 Manual & & & & & & \\
\hline New WinBox & & & & & & \\
\hline 园 Exit & & & & & & \\
\hline
\end{tabular}

Gambar 8Tampilan IP Address

5. Tampilan Firewall NAT

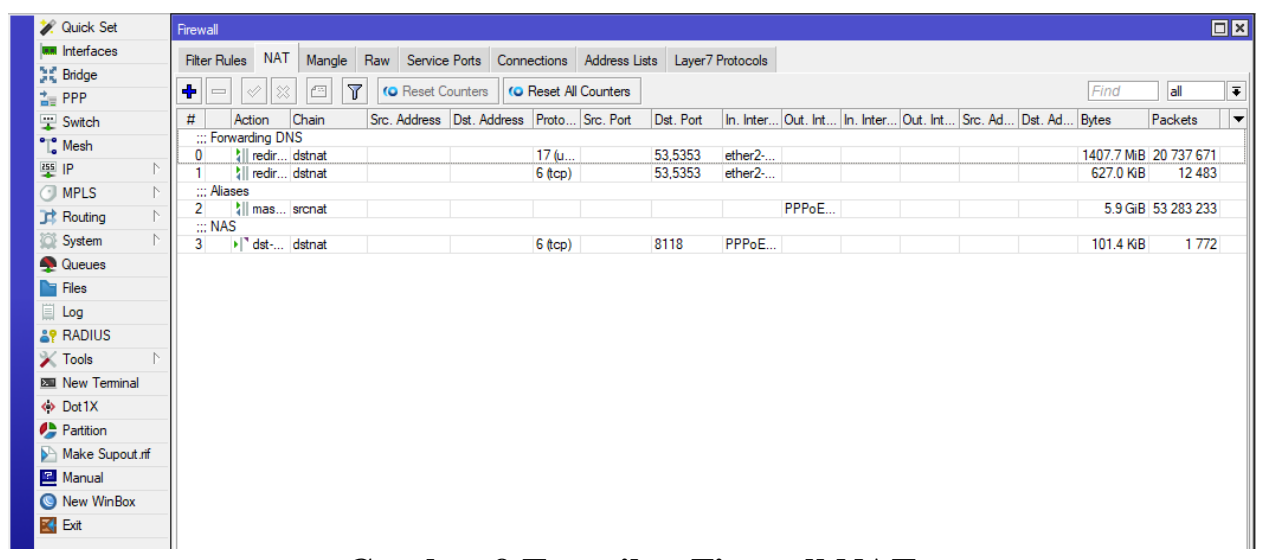

Gambar 9 Tampilan Firewall NAT

\section{TampilanDNS}

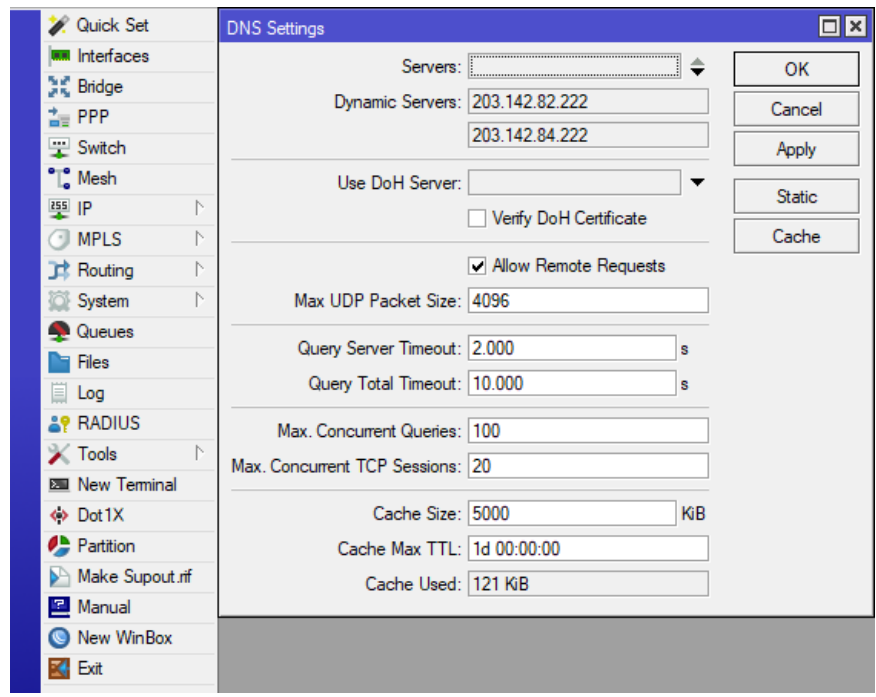


Gambar 10 Tampilan DNS

7. TampilanFirewall Raw

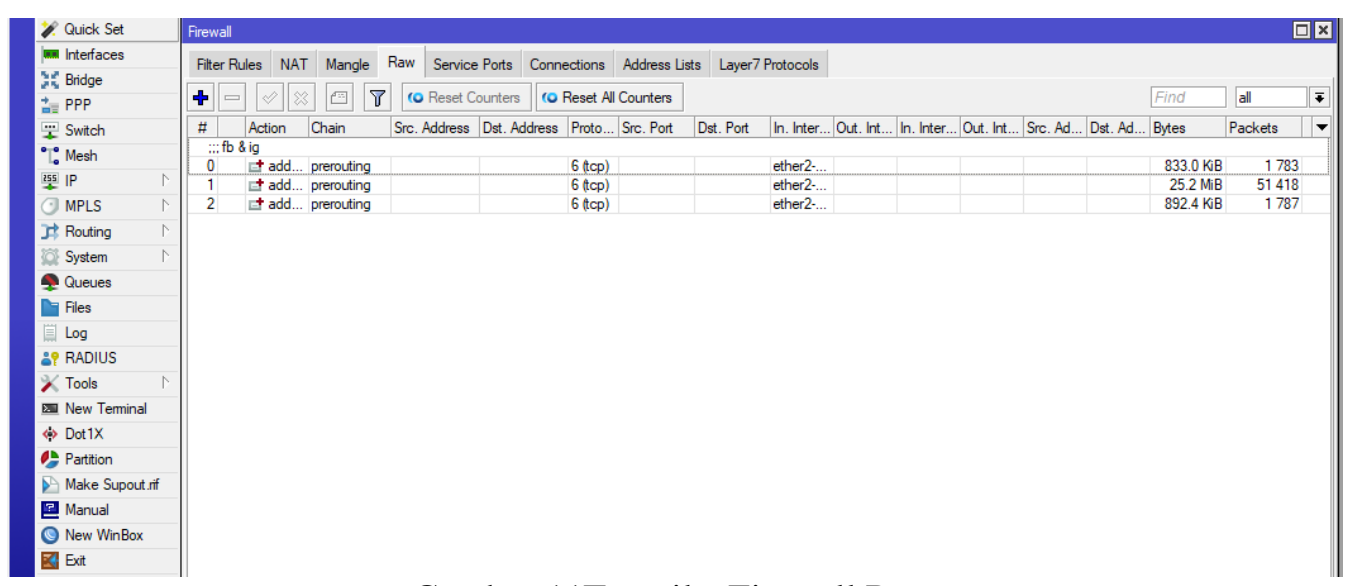

Gambar 11TampilanFirewall Raw

8. Tampilan Firewall Address list

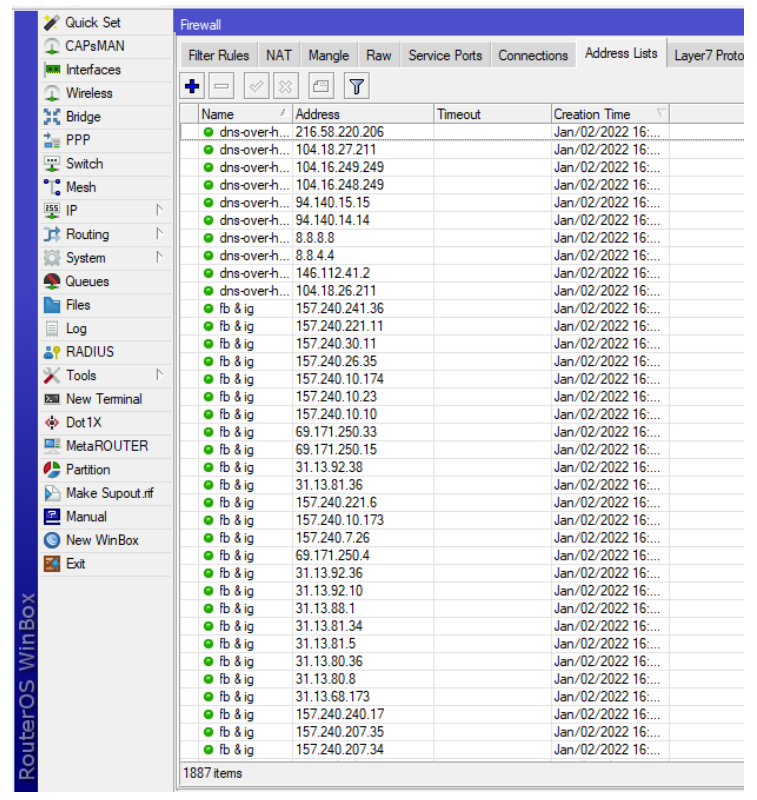

Gambar 12Tampilan Address list

9. Tampilan Firewall Mangle 


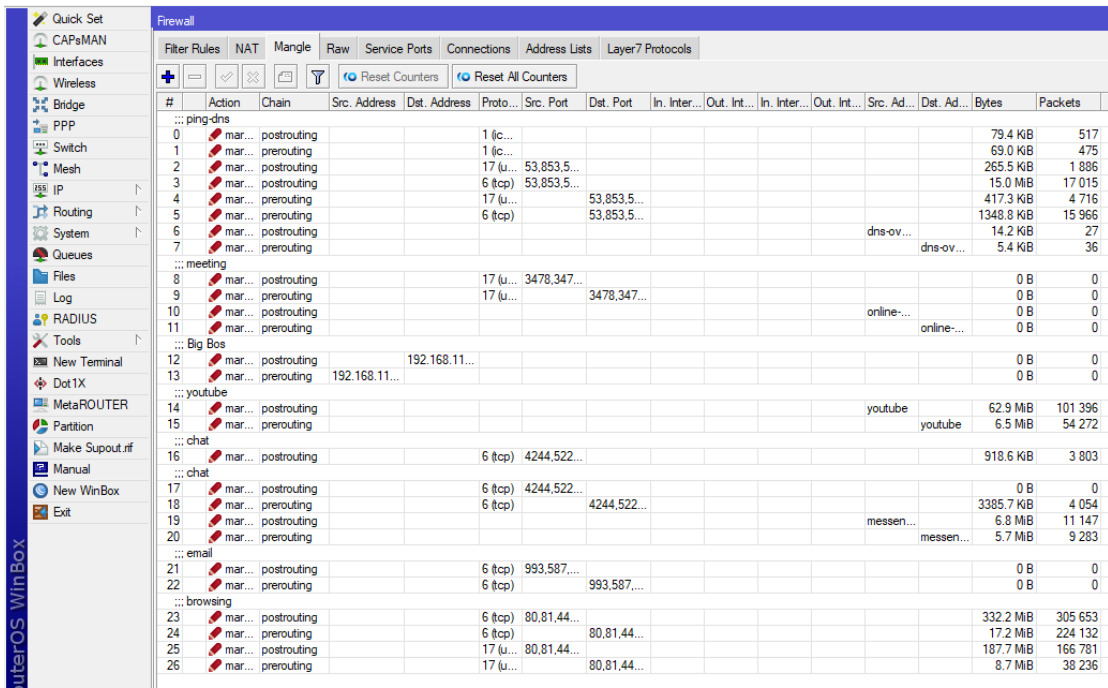

Gambar 13Tampilan Firewall Mangle

\section{Tampilan Queue}

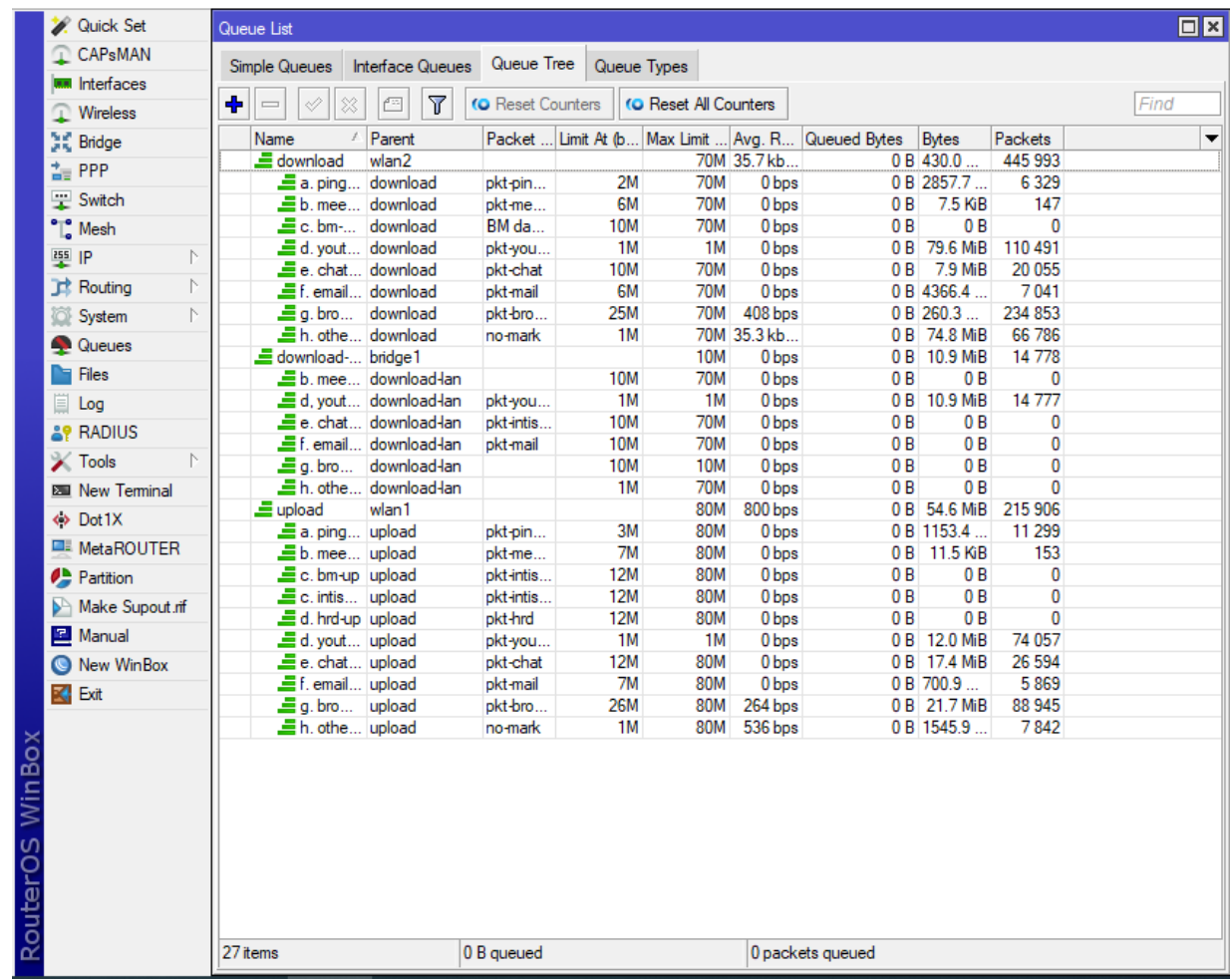

Gambar 14 TampilanQueue 


\section{KESIMPULAN}

Berdasarkan penelitian dan pengamatan yang telah dilakukan, maka penelitian ini dapat disimpulkan sebagai berikut :

1. Dalam Sistem Jaringan internet yang berjalan saat ini, menggunakan pembagian bandwidth berdasarkan IP. Dengan kondisi saat ini penggunaan internet dengan device yang tidak menentu atau bersifat dinamis seperti HP dan Laptop maka diperlukannya metode Hierarchical Token Bucket sebagai pembagian bandwidth.

2. Penggunaan metode Hierarchical Token Bucket (HTB) dapat mengontrol bandwidth internet yang digunakan oleh setiap client. Dengan metode ini client mendapatkan paket sesuai dengan kebutuhan prioritas yang sudah ditentukan.

3. Client yang bersifatnya dinamis tidak perlu pengajuan terhadap penggunaan akses internet, IP yang didapatkan sudah terhubung dengan akses internet.

\section{DAFTAR PUSTAKA}

[1] Puspitasari, Nila Feby., dan Dahlan, Akhmad. 2017. Analisa Trafik Dan Quality Of Service (Qos) Untuk Optimalisasi Manajemen Bandwidth (Studi Kasus : Universitas AMIKOM Yogyakarta).

[2] Ontoseno, R Dion Handoyo., Haqqi, Muhammad Nurul., dan Hatta, Moch. 2017. LimitasiPengguna Akses Internet Berdasarkan Kuota Waktu dan Data Menggunakan PC Router OS Mikrotik ( Studi Kasus : SKM YPM 7 Tarik).

[3] Rouf, dan Dliyaur,Muhammad. 2017. Manajemen Bandwidth Dalam Jaringan Warnet Dengan Metode PCQ. Yogyakarta: Universitas Mercu Buana.

[4] Risna, R., Isnawaty, I., \& Sutardi, S. Optimalisasi Jaringan Wireless Dan Analisis Quality Of Service (QoS) Menggunakan Metode Hierarchical Token Bucket (HTB). semanTIK, $3(2)$.

[5] Riady, Alvin, and Aan Restu Mukthi."Penerapan Manajemen Bandwith Menggunakan Hierarchical Token Bucket Di PT. Bukit Energi Servis Terpadu."Jurnal Pengembangan Sistem Informasi dan Informatika 2.2 (2021): 87-96.

[6] Sidqi, Tri Oktafi, and Novi Dian Nathasia."Implementasi Manajemen Bandwith Menggunakan Metode HTB (Hierarchical Token Bucket) Pada Jaringan Mikrotik."JIPI (Jurnal Ilmiah Penelitian dan Pembelajaran Informatika) 6.1 (2021): 132-138.

[7] Haryani, Prita, et al. ManajemenPadaJaringanMikrotikMenggunakanMetode Hierarchical Token Bucket (HTB) Dan Keamanan Firewall Intrusion Detection System (IDS). JurnalJarkom, 2021, 9.1: 1-9.

[8] M Daffa, Aliffandhana, Asrowardi Imam, and Kania Widyawati Dewi."Desain Infrastruktur Jaringan Komputer dengan Metode Hierarchical Token Bucket menggunakan Mikrotik pada Badan Kesatuan Bangsa dan Politik."Karya Ilmiah Mahasiswa (2019).

[9] Octavianto, Tobby. "Pemanfaatan Hierachical Token Bucket Dalam Konsep Jaringan Untuk Pengoptimalan Bandwidth."Journal of Information and Technology 1.2 (2021): 43-46. 
[10] Putra, Ketut Gede Widia Pratama. Penerapan Manajemen Bandwidth Menggunakan Metode Hierarchical Token Bucket Pada Layanan Hotspot Mikrotik Undiksha. Diss. Universitas Pendidikan Ganesha, 2020.

[11] Fadli, Ardian. "Implementasi Quality Of Service pada Campus Network Menggunakan Teknologi Software-Defined Networking dan Open day light Controller dengan Metode Hierarchical Token Bucket." (2018).

[12] Sugianto, Sugianto, and Mimin F. Rohmah."PERBANDINGAN PERFORMANCE MANAGEMEN BANDWIDTH METODE HIERARCHICAL TOKEN BUCKET (HTB) DAN PER CONNECTION QUEUE MENGGUNAKAN MIKROTIK RB450G."Prosiding SNP2M (Seminar Nasional Penelitian dan Pengabdian Masyarakat) UNIM.No. 1. 2019

[13] Manalu, Esdinar, Diki Arisandi, and Sukri Sukri."Analisa Management Bandwidth Dengan Metode Antrian Hirarchical Token Bucket."Prosiding CELSciTech 2 (2017): tech_10tech_17.

[14] Patandung, Ebenhaezer, S. T. Wiwin Sulistyo, and M. Kom. "Analisis Quality of Service (QoS) Video Streaming Dengan Menggunakan Metode Differentiated Service dan Hierarchical Token Bucket." 